\title{
Study on the Accumulation of Heavy Metals in Alpinia Oxyphylla Miq. at Different Growth Stages
}

\author{
Dan Zhou ${ }^{1, a^{*}}$, Yurong $\mathrm{Fu}^{1, \mathrm{~b}}$, Weiyong Lai ${ }^{2, \mathrm{c}}$ and Junqing Zhang ${ }^{2, \mathrm{~d}^{*}}$ \\ ${ }^{1}$ School of Pharmacy, Hainan Medical University, Haikou,China \\ ${ }^{2}$ Hainan Provincial Key Laboratory of Research and Development of Tropical Medicinal Plants, \\ Hainan Medical University,Haikou, China

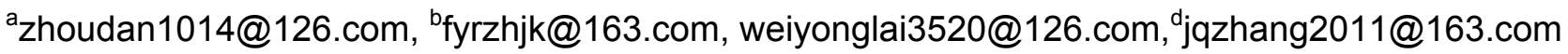 \\ * Correspondence
}

Keywords: Alpinia oxyphylla Miq; heavy metals; best harvest time

Abstract. Objective: to compare the contents of heavy metals in Alpinia oxyphylla Miq. at different growth stages. Methods: The content of $\mathrm{Cu}$ was determined by atomic absorption spectroscopy. The contents of other four elements, i.e. $\mathrm{As}, \mathrm{Hg}, \mathrm{Pb}$ and $\mathrm{Cd}$, were determined by atomic fluorescence spectroscopy. Result: the contents of heavy metals in fruit and rhizome of Alpinia oxyphylla Miq. were lower than the criteria for the limit content of heavy metals issued by Green Trade Standards of Importing \& Exporting Medicinal Plants \& Preparations at different growth stages. The content of heavy elements was the lowest at the ripe fruit of the $40^{\text {th }}$ day. Conclusion: The $40^{\text {th }}$ day was the best harvest time for Alpinia oxyphylla Miq.

\section{Introduction}

In recent years, whether the contents of heavy metals in Chinese herbal medicine were consistent with The Green Trade Standards or not had become the challenge of Chinese medicinal materials' import and export. Green Trade Standards of Importing \& Exporting Medicinal Plants \& Preparations, which was awarded by the State Department of Commerce in 2001, had set bounds to the contents of heavy elements in medicinal plants. Therefore, research on the role of heavy metals in Chinese herbaceous plants had become an area of particular concern and high priority in environmental research and protection ${ }^{[1-3]}$.

Alpinia oxyphylla Miq. was a dry ripe fruit of herbaceous perennial, which belongs to Zingiberaceae, and is mainly produced in Hainan, Guangdong, Guangxi and Yunnan provinces ${ }^{[4]}$. Its capsular fruits were commonly used in traditional East Asian medicine for treating diarrhea ${ }^{[5]}$, intestinal disorders ${ }^{[6]}$, dieresis ${ }^{[7]}$, frequent ruination and urinary incontinence ${ }^{[8]}$.

Modern pharmacological studies had shown that Alpinia oxyphylla Miq. had many pharmacological effects such as anti-inflammatory activities, anti-allergy, anti-ulcer and neuroprotective roles ${ }^{[9,10]}$.

Chemical analysis revealed that Alpinia oxyphylla Miq. contained flavonoids, diarylheptanoids, sesquiterpenes, volatile oil, steroids and their glycosides, etc ${ }^{[11,12]}$. Our lab also reported the content levels of nine representative compounds occurring in the fruits of Alpinia oxyphylla Miq. harvested at different stages ${ }^{[10]}$. However, the major constituents are only emphasized aiming at current drug safety of Alpinia oxyphylla Miq., and the results were inadequate for the whole quality assurance purposes of Alpinia oxyphylla Miq. Therefore, a powerful analysis approach for identification and simultaneous determination of heavy metals in Alpinia oxyphylla Miq. was urgently needed to ensure the quality control, efficacy and safety of Chinese patent drug.

In the study, the contents of heavy metals in Alpinia oxyphylla Miq. at different growth time were determined. The research would provide the scientific basis for the quality control and safe medication of Alpinia oxyphylla Miq. Meanwhile, it could provide data reference for the acquisition time and GAP (Good Agricultural Practice of Medicinal Plants and Animals) specification planting of Alpinia oxyphylla Miq. 


\section{Experimental}

\section{Apparatus}

3510 atomic absorption spectrophotometry(Agilent Technologies Instrument Co., Ltd, Shanghai, China) equipped with $\mathrm{Cu}$ hollow cathode lamps(Beijing Titan Instruments Co., Ltd, Beijing, China) was used in measurement. A model AFS 830 sequential injection vapor generation double-channel non-dispersive atomic fluorescence spectrometry (Beijing Titan Instruments Co., Ltd, Beijing, China) equipped with $\mathrm{As}, \mathrm{Hg}, \mathrm{Pb}$ and $\mathrm{Cd}$ hollow cathode lamps (Beijing Titan Instruments Co., Ltd, Beijing, China) was used. A LabTech EG20A electric hot plate (Beijing Titan Instruments Co., Ltd, Beijing, China) was employed for sample preparation.

\section{Reagents}

All reagents were of highest available purity and were at least analytical grade. Ultrapure water was used throughout the experiment.

Chemicals and reagents used throughout the work were of hyper-pure grade. Certified stock standards $\left(1000 \mathrm{mg} \cdot \mathrm{L}^{-1}\right.$, each) for $\mathrm{As}, \mathrm{Hg}, \mathrm{Pb}$ and $\mathrm{Cd}$ were purchased from National Research Center for Certified Reference Materials (NRCCRM, China). Dilutions of standards and samples were done by using deionized water $(18.2 \mathrm{M} \Omega \mathrm{cm})$. These reagents, such as hydrochloride, nitric acid, sulfuric acid, dithizone, carbon tetrachloride, potassium hydroxide, cobalt chloride, thiourea, oxalic acid, potassium ferricyanide, ascorbic acid, lanthanum nitrate, were purchased from Guangzhou Chemical Reagent Factory. Potassium borohydride was purchased from Sinopharm Chemical Reagent Co., Ltd.

\section{Sample collection}

14 samples of different parts of Alpinia oxyphylla Miq. (fruit, rhizome, stem and leaf) at different growth stages were collected, respectively including $5^{\text {th }}, 10^{\text {th }}, 15^{\text {th }}, 20^{\text {th }}, 25^{\text {th }}, 27^{\text {th }}, 30^{\text {th }}, 35^{\text {th }}, 40^{\text {th }}, 45^{\text {th }}$, $50^{\text {th }}, 55^{\text {th }}, 60^{\text {th }}$ and $65^{\text {th }}$ day. Each sample was $100 \mathrm{~g}$.

Botanical identification and authentication of the collected species with depositions of herbarium specimens had been done by Jian-ping Tian, associate professor of Hainan Medical University.

\section{Sample preparation}

Powdered samples with the weight of $1000 \mathrm{~g}$ were weighed and transferred into $100-\mathrm{mL}$ conical flask and mixed with $\mathrm{HNO}_{3} 10 \mathrm{~mL}$ and $\mathrm{HClO}_{4} 2 \mathrm{~mL}$. The samples were soaked overnight after all digestion reagents were added. Then, the flask was placed on the electric hot plate for digesting until the white smoke appeared. However, this operation had to be handled gently, thereby ensuring that the digestion solution cannot be heated to dryness. The digested solution was transferred to a $25-\mathrm{mL}$ volumetric flask after being cooled, $100 \mathrm{~g} \cdot \mathrm{L}^{-1}$ thiourea solution $5 \mathrm{~mL}$ was mixed, which was then diluted to $25 \mathrm{~mL}$ with $1.5 \% \mathrm{HCl}$. The solution was set aside for $30 \mathrm{~min}$ at room temperature for the determining $\mathrm{As}, \mathrm{Hg}$ and $\mathrm{Cu}^{[13]}$.

Powdered samples $1000 \mathrm{~g}$ were weighed and prepared according to the same method for preparing solution of As. Then, the samples were digested until the digestion solution was heated to dryness. The remaining material was dissolved by $1.5 \% \mathrm{HNO}_{3}$ after being cooled. The digesting solution was transferred to a $25-\mathrm{mL}$ volumetric flask, which was then diluted to $25 \mathrm{~mL}$ with $1.5 \% \mathrm{HNO}_{3}$. This solution was set aside for $30 \mathrm{~min}$ at room temperature for determining $\mathrm{Pb}$.

Powdered samples $1000 \mathrm{~g}$ were weighed, prepared and digested according to the same method for preparing for the solution of $\mathrm{Pb}$. The remaining material was dissolved by $0.2 \mathrm{~mol} \cdot \mathrm{L}^{-1} \mathrm{H}_{2} \mathrm{SO}_{4}$ after being cooled. The digesting solution was transferred to a $25-\mathrm{mL}$ volumetric flask, and $0.5 \mathrm{~g} \cdot \mathrm{L}^{-1}$ dithizone carbon tetrachloride solution $5 \mathrm{~mL}$ was mixed. $50 \mathrm{~g} \cdot \mathrm{L}^{-1}$ sulfuric acid solution $10 \mathrm{~mL}$ and $0.10 \mu \mathrm{g} \cdot \mathrm{L}^{-1}$ cobalt chloride solution $0.5 \mathrm{~mL}$ were mixed after being shocked fiercely for $2 \mathrm{~min}$, which was then diluted to $25 \mathrm{~mL}$ with $0.2 \mathrm{~mol} \cdot \mathrm{L}^{-1} \mathrm{H}_{2} \mathrm{SO}_{4}$. This solution was set aside for $30 \mathrm{~min}$ at room temperature for determining $\mathrm{Cd}$.

Blank solutions were prepared in a similar way, and the same final concentrations were achieved. Certified stock standards $\left(1000 \mathrm{mg} \cdot \mathrm{L}^{-1}\right.$, each) of $\mathrm{As}, \mathrm{Hg}, \mathrm{Pb}, \mathrm{Cd}$ and $\mathrm{Cu} 1 \mathrm{~mL}$ were mixed, which was then diluted to $1.000 \mathrm{mg} \cdot \mathrm{L}^{-1}$ with $3 \% \mathrm{HNO}_{3}$ as calibration solution. 


\section{Instrument parameters}

The content of $\mathrm{Cu}$ was determined by atomic absorption spectroscopy(AAS), and the contents of other four elements, i.e. $\mathrm{As}, \mathrm{Hg}, \mathrm{Pb}$ and $\mathrm{Cd}$, were determined by atomic fluorescence spectroscopy(AFS). The instrument parameters of AAS and AFS were respectively shown in Table 1 and Table 2.

Table 1 the parameters for Atomic fluorescence spectroscopy(AFS) measurement

\begin{tabular}{|c|c|c|c|c|c|}
\hline Element & $\begin{array}{l}\text { Lamp } \\
\text { current }\end{array}$ & $\begin{array}{l}\text { Atomizer } \\
\text { temperature }\end{array}$ & $\begin{array}{l}\text { Atomizer } \\
\text { height }\end{array}$ & Reductant & Carrier liquid \\
\hline As & $60 \mathrm{~mA}$ & $200^{\circ} \mathrm{C}$ & $8.0 \mathrm{~mm}$ & $20 \mathrm{~g} \cdot \mathrm{L}^{-1} \mathrm{KBH}_{4}$ & $5 \% \mathrm{HCl}$ \\
\hline $\mathrm{Hg}$ & $25 \mathrm{~mA}$ & $200^{\circ} \mathrm{C}$ & $8.0 \mathrm{~mm}$ & $20 \mathrm{~g} \cdot \mathrm{L}^{-1} \mathrm{KBH}_{4}$ & $2 \% \mathrm{HNO}_{3}$ \\
\hline $\mathrm{Pb}$ & $80 \mathrm{~mA}$ & $200^{\circ} \mathrm{C}$ & $8.0 \mathrm{~mm}$ & $\begin{array}{l}30 \mathrm{~g} \cdot \mathrm{L}^{-1} \mathrm{KBH}_{4}, 100 \mathrm{~g} \cdot \mathrm{L}^{-1} \mathrm{~K}_{3} \mathrm{Fe}(\mathrm{CN} \\
)_{6}\end{array}$ & $1.6 \% \mathrm{HCl}$ \\
\hline $\mathrm{Cd}$ & $80 \mathrm{~mA}$ & $200^{\circ} \mathrm{C}$ & $8.0 \mathrm{~mm}$ & $30 \mathrm{~g} \cdot \mathrm{L}^{-1} \mathrm{KBH}_{4}$ & $\begin{array}{l}0.20 \mathrm{~mol} \cdot \mathrm{L}^{-1} \\
\mathrm{H}_{2} \mathrm{SO}_{4}\end{array}$ \\
\hline
\end{tabular}

Table 2 the parameters for Atomic absorption spectroscopy(AAS) measurement

\begin{tabular}{ccccc}
\hline Element & Wavelength & Lamp current & Slit & The ratio of combustion air to acetylene \\
\hline $\mathrm{Cu}$ & $324.7 \mathrm{~nm}$ & $2 \mathrm{~mA}$ & $0.2 \mathrm{~nm}$ & $8: 1.5$ \\
\hline
\end{tabular}

\section{The standard curve}

Standard solution $\left(1.00 \mathrm{mg} \cdot \mathrm{L}^{-1}\right)$ for As with volume of $0.00,0.20,0.50,1.00,2.00$ and $5.00 \mathrm{~mL}$ was respectively transferred into $100-\mathrm{mL}$ volumetric flask, and standard solution $\left(0.10 \mathrm{mg} \cdot \mathrm{L}^{-1}\right)$ for $\mathrm{Hg}$ $0.00,0.10,0.20,0.50,1.00$ and $2.00 \mathrm{~mL}$ was then added into each volumetric flask, which was mixed with hydrochlorie $5.0 \mathrm{~mL}$ and $100 \mathrm{~g} \cdot \mathrm{L}^{-1}$ ascorbic acid thiourea solution $20 \mathrm{~mL}$, which was then diluted to $100 \mathrm{~mL}$. The solutions were set aside for $30 \mathrm{~min}$ at room temperature for determining As and $\mathrm{Hg}$.

Standard solution $\left(1.00 \mathrm{mg} \cdot \mathrm{L}^{-1}\right)$ for $\mathrm{Pb}$ with volume of $0.00,0.50,1.00,2.00,4.00$ and $8.00 \mathrm{~mL}$ was respectively transferred into $100-\mathrm{mL}$ volumetric flask, which was then diluted to $100 \mathrm{~mL}$ with $1.5 \%$ $\mathrm{HNO}_{3}$. The solutions were set aside for $30 \mathrm{~min}$ at room temperature for determining $\mathrm{Pb}$.

Standard solution $\left(0.1 \mathrm{mg} \cdot \mathrm{L}^{-1}\right)$ for Cd with volume of $0.00,0.50,1.00,2.00,4.00$ and $8.00 \mathrm{~mL}$ was respectively transferred into $100-\mathrm{mL}$ volumetric flask, which was mixed with dithizone carbon tetrachloride solution. $50 \mathrm{~g} \cdot \mathrm{L}^{-1}$ sulfuric acid solution $20 \mathrm{~mL}$ and $0.10 \mu \mathrm{g} \cdot \mathrm{L}^{-1}$ cobalt chloride solution $2.0 \mathrm{~mL}$ were mixed after being shocked fiercely for $2 \mathrm{~min}$, which wasthen diluted to $100 \mathrm{~mL}$ with $0.20 \mathrm{~mol} \cdot \mathrm{L}^{-1} \mathrm{H}_{2} \mathrm{SO}_{4}$. The solutions were set aside for $30 \mathrm{~min}$ at room temperature for determining $\mathrm{Cd}$.

Standard solution $100 \mathrm{mg} \cdot \mathrm{L}^{-1}$ for $\mathrm{Cu}$ with volume of $0.00,0.20,0.50,1.00,1.50$ and $2.00 \mathrm{~mL}$ was

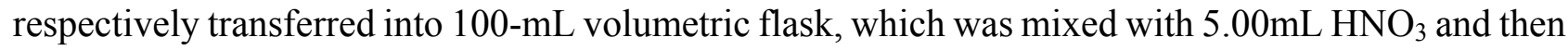
diluted to $100 \mathrm{~mL}$. The solutions were set aside for $30 \mathrm{~min}$ at room temperature for determining $\mathrm{Cu}$ by AAS.

These solutions were determined by AAS or AFS. Then the calibration curves for $\mathrm{As}, \mathrm{Hg}, \mathrm{Pb}, \mathrm{Cd}$ and $\mathrm{Cu}$ were drawn.

\section{Results and Discussion}

\section{Method validation}

Standard curve

The calibration curves were linear up to $50 \mu \mathrm{g} \cdot \mathrm{L}^{-1}$ for As, $2 \mu \mathrm{g} \cdot \mathrm{L}^{-1}$ for $\mathrm{Hg}, 8 \mu \mathrm{g} \cdot \mathrm{L}^{-1}$ for $\mathrm{Pb}$ and $\mathrm{Cd}$, and $2 \mathrm{mg} \cdot \mathrm{L}^{-1}$ for $\mathrm{Cu}$. The linear correlations were all between 0.9985 and 0.9999 . The favorable correlation showed evidence for the reliability of the proposed method.

\section{Accuracy tests}

The accuracy of the method was also evaluated by recovery experiments, which was carried out by using samples with known concentrations of $\mathrm{As}, \mathrm{Hg}, \mathrm{Pb}, \mathrm{Cd}$ and $\mathrm{Cu}$, and analyzed for 6 times according to the test method. The RSD of 6 parallel tests was $1.7 \%$ for $\mathrm{As}, 2.7 \%$ for $\mathrm{Hg}, 1.4 \%$ for $\mathrm{Pb}$, $2.1 \%$ for $\mathrm{Cd}$ and $0.0 \%$ for $\mathrm{Cu}$. 


\section{Repeatability tests}

Powdered samples with the weight of $1000 \mathrm{~g}$ were weighed, prepared and analyzed for 3 times according to the test method. The RSD of repeatability tests was $3.9 \%$ for $\mathrm{As}, 1.7 \%$ for $\mathrm{Hg}, 0.72 \%$ for $\mathrm{Pb}, 3.9 \%$ for $\mathrm{Cd}$ and $2.2 \%$ for $\mathrm{Cu}$.

\section{Recovery tests}

Powdered samples $0.5000 \mathrm{~g}$ were weighed, and mixed with different calibration solutions (at higher, middle, and lower levels) of each element, which were then prepared and analyzed according to the test method. Each sample with the same calibration solution was prepared for 3 parallel tests. The results of recovery test were shown in table 3 . The recoveries of each element ranged from $93.4 \%$ to $104.2 \%$.

Table 3 The result of recovery test $(n=9)$

\begin{tabular}{lllllll}
\hline $\begin{array}{l}\text { Elemen } \\
\mathrm{t}\end{array}$ & $\begin{array}{l}\text { Content of } \\
\text { sample }(\mu \mathrm{g} / \mathrm{g})\end{array}$ & $\begin{array}{l}\text { Mass of added } \\
\text { certified element }(\mu \mathrm{g} / \mathrm{g})\end{array}$ & $\begin{array}{l}\text { Content by } \\
\text { analyzed } \\
(\mu \mathrm{g} / \mathrm{g})\end{array}$ & $\begin{array}{l}\text { Recoverie } \\
\mathrm{s} \\
(\%)\end{array}$ & $\begin{array}{c}\text { Average } \\
\text { recoveries(\%) }(\%)\end{array}$ & $\begin{array}{l}\text { RSD } \\
(\%)\end{array}$ \\
\hline $\mathrm{As}$ & 0.3754 & 0.4500 & 0.7824 & 90.5 & & \\
& & 0.5500 & 0.9265 & 108.8 & 93.4 & 2.6 \\
& & 0.6600 & 1.0134 & 92.9 & & \\
\hline $\mathrm{Hg}$ & 0.0409 & 0.0180 & 0.0626 & 94.4 & & 1.8 \\
& & 0.0230 & 0.0677 & 101.3 & 102.8 & \\
& & 0.0270 & 0.0718 & 112.8 & & \\
\hline $\mathrm{Pb}$ & 0.3791 & 0.3000 & 0.7086 & 109.8 & & \\
& & 0.3800 & 0.7643 & 101.4 & 101.9 & \\
& & 0.4600 & 0.8132 & 94.4 & & \\
$\mathrm{Cd}$ & 0.0379 & 0.0120 & 0.0514 & 112.8 & & \\
& & 0.0150 & 0.0519 & 93.5 & 104.2 & \\
& & 0.0190 & 0.0582 & 106.3 & & \\
\hline $\mathrm{Cu}$ & 21.50 & 3.000 & 24.75 & 108.3 & & \\
& & 4.000 & 24.13 & 93.8 & 101.6 & \\
\end{tabular}

\section{Contents of heavy elements of samples at different growth stages}

\section{Contents of heavy elements of different parts of Alpinia oxyphylla Miq.}

The accumulation of heavy metals such as $\mathrm{As}, \mathrm{Hg}, \mathrm{Pb}, \mathrm{Cd}$ and $\mathrm{Cu}$ was determined in fruit, rhizome, stem and leaf of Alpinia oxyphylla Miq. The results were shown in table 4.

Table 4 Contents of heavy metals in different parts of Alpinia oxyphylla Miq. $\left(\mu \mathrm{g}^{\cdot} \mathrm{g}^{-1}\right)$

\begin{tabular}{cccccc}
\hline & $\mathrm{As}$ & $\mathrm{Hg}$ & $\mathrm{Pb}$ & $\mathrm{Cd}$ & $\mathrm{Cu}$ \\
\hline Fruit & 0.2604 & 0.0220 & 0.1000 & 0.0360 & 7.300 \\
Rhizome & 0.7266 & 0.1450 & 0.1832 & 0.0210 & 8.350 \\
Stem and leaf & 0.4413 & 0.1480 & 0.0782 & 0.0080 & 9.025 \\
\hline
\end{tabular}

The accumulation of heavy metals such as $\mathrm{As}, \mathrm{Hg}, \mathrm{Pb}$ and $\mathrm{Cu}$ in Alpinia oxyphylla Miq. was lower in fruit than that in rhizome, stem and leaf. While the content was higher in fruit than that in rhizome, stem and leaf aiming at $\mathrm{Cd}$. In a whole, the contents of heavy metals were lower than that in other parts of Alpinia oxyphylla Miq.

\section{Contents of heavy elements of Alpinia oxyphylla Miq. at different growth stages}

Contents of heavy metals of samples at different stages were analyzed. The results were shown in Fig 1.

The changes of contents of As in fruit, rhizome, stem and leaf were listed in Fig.1(a).The contents of As in fruit had changed in the whole growth stages, which reached four peak times. However, the lowest content was discovered in the $40^{\text {th }}$ day. The contents of As in stem and leaf had kept stable. 
When the fruit was matured, the content of As in fruit seemed higher, but it was much lower than that in rhizome. The result showed that As had migrated from fruit into rhizome, stem and leaf, especially in rhizome.

The results could be drawn from Fig.1(b). In the whole stage, the content of $\mathrm{Hg}$ was extremely lower in fruit, steam and leaf, but it had a volatility in rhizome, which was lower between $5^{\text {th }}$ day and $30^{\text {th }}$ day. The content was gradually rising from the $30^{\text {th }}$ to the $40^{\text {th }}$ day, and reached peak in the $40^{\text {th }}$ day, which was then gradually reduced after the $45^{\text {th }}$ day.

Fig.1(c) shows that the content of $\mathrm{Pb}$ was higher in fruit than that in rhizome, steam and leaf in the whole grown stage, and it had four peak times. The content was lower in the $10^{\text {th }}, 25^{\text {th }}, 45^{\text {th }}$ and $60^{\text {th }}$ day, and it reached the lowest level in the $60^{\text {th }}$ day.

From Fig.1(d) shows that the content of Cd was higher in fruit, steam and leaf than that in rhizome in the whole stage, and it had four peak times. The content was lower in fruit in the $10^{\text {th }}, 25^{\text {th }}, 30^{\text {th }}$, $40^{\text {th }}, 55^{\text {th }}$ and $60^{\text {th }}$ day. It reached the lowest level in the $30^{\text {th }}$ day in fruit, while the content of Cd was lower in the $15^{\text {th }}, 30^{\text {th }}, 50^{\text {th }}$ and $60^{\text {th }}$ day in steam and leaf.

Fig.1(e) shows that the content of $\mathrm{Cu}$ in fruit was much higher than that in rhizome, steam and leaf. It reached the lowest level in the $40^{\text {th }}$ day.

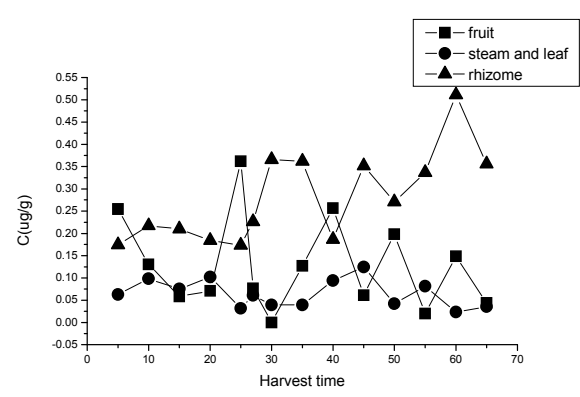

(a)As

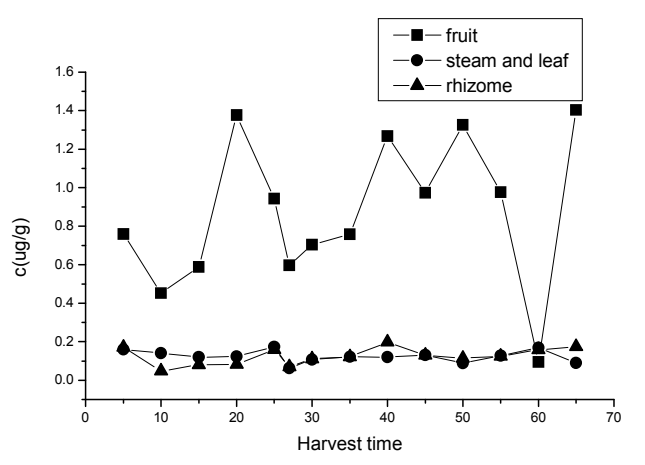

(c) $\mathrm{Pb}$

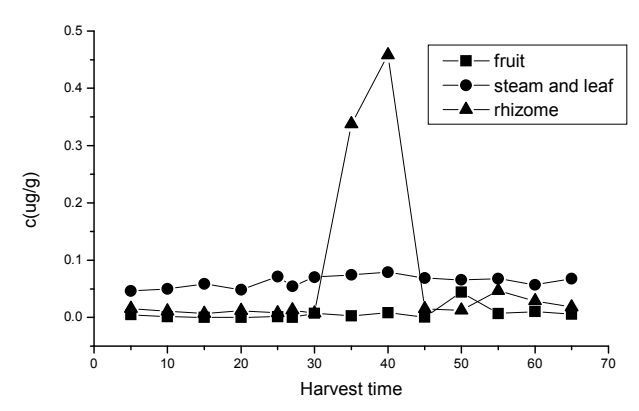

(b) $\mathrm{Hg}$

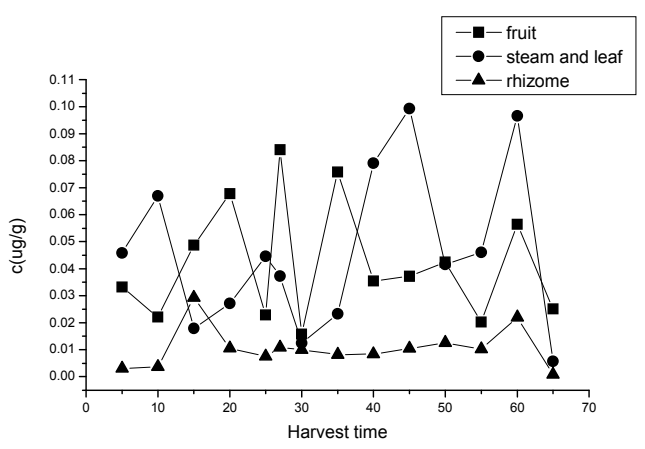

(d) $\mathrm{Cd}$

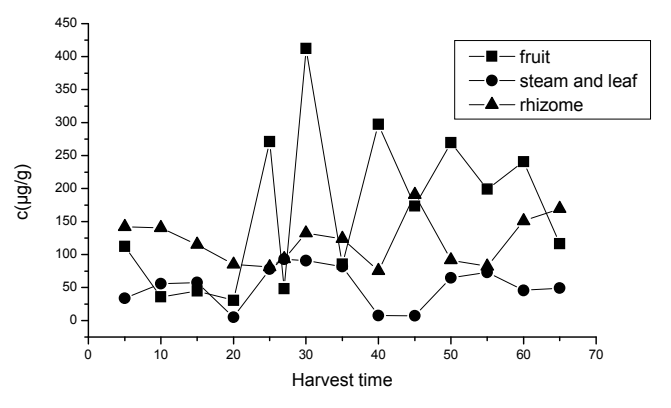

(e) $\mathrm{Cu}$

Fig.1 Change of content of $\mathrm{As}, \mathrm{Hg}, \mathrm{Pb}, \mathrm{Cd}, \mathrm{Cu}$ in different parts of Alpinia oxyphylla Miq. at different grown stages 
It is discovered according to changes of contents of heavy metals in fruit, rhizome, steam and leaf in the whole grown stage that the contents of heavy metals were lower in fruit and rhizome. The best harvest time is the $40^{\text {th }}$ day.

\section{Conclusion}

The contents of heavy metals such as $\mathrm{As}, \mathrm{Hg}, \mathrm{Pb}$ and $\mathrm{Cd}$ were determined by AFS. The content of $\mathrm{Cu}$ was determined by AAS. The methodology validation showed that the precision and accuracy of the method were in line with requirements.

The contents of heavy metals in different parts of Alpinia oxyphylla Miq. were determined, and the results showed that the contents of heavy metals were lower in fruit and rhizome. It was safe to use fruit and rhizome of Alpinia oxyphylla Miq. as a medicine.

The best harvest time of Alpinia oxyphylla Miq. was the $40^{\text {th }}$ day and the contents of heavy metals were $0.609 \mu \mathrm{g} \cdot \mathrm{g}^{-1}$ for As, $0.0007 \mu \mathrm{g} \cdot \mathrm{g}^{-1}$ for $\mathrm{Hg}, 0.9729 \mu \mathrm{g} \cdot \mathrm{g}^{-1}$ for $\mathrm{Pb}, 0.0372 \mu \mathrm{g} \cdot \mathrm{g}^{-1}$ for $\mathrm{Cd}$ and $173.5 \mu \mathrm{g} \cdot \mathrm{g}^{-1}$ for $\mathrm{Cu}$.

Green Trade Standards of Importing \& Exporting Medicinal Plants \& Preparations, which was awarded by the State Department of Commerce of China in 2001, had set bounds to the contents of heavy elements in medicinal plants. As to the phenomenon that the contents of the harmful heavy metals in some traditional Chinese medicines (TCM) were excessive, it was suggested to do from the source, and large cultivation bases of Chinese medicinal materials should be established, which were consistent with GAP. Heavy metals pollution should be strictly controlled from the place, environment control, seed selection, planting, cultivation and acquisition process. At the same time, GMP (good manufacturing practice) should be strictly carried out through the whole process of pharmaceutical production.

The research would provide the scientific basis for the resource utilization of the rhizome, stem and leaf of Alpinia oxyphylla Miq.

\section{Acknowledgement}

The authors wish express their thanks to Feng Chen (Hainan Medical University, Haikou, China),Yong-hui Li(Hainan Medical University, Haikou, China),Jian-ping Tian(Hainan Medical University, Haikou, China) and Yong Wang (Hainan Medical University, Haikou, China)for their help in collecting Alpinia oxyphylla Miq.A.oxyphylla from Qiongzhong town in Hainan province. This work was supported by Grant Hjkj2013-28 from the Education Department of Hainan Province.

\section{References}

[1] Jun Xue, Shengfang Gong, Xingmei Wang, et al. Analytical Letters, Vol. 45(2012), p. 2257 -2268 .

[2] Ammar Mubark Ebrahim . Mohamed Hassan Eltayeb. Hassan Khalid. Haidar Mohamed . Nat Med, Vol. 66(2012), p. 671-679.

[3] Aydın Akbulut. Nuray Emir Akbulut. Environ Monit Assess , Vol. 167(2010), p. 521-526.

[4] Chinese Pharmacopoeia Commission. Pharmacopoeia of the People's Republic of China, China Medical Science and Technology Press: Beijing, China, Vol. 1(2010), p. 273-274.

[5] Feng Chen, Hai-long Li, Yinfeng Tan, et al. Molecules, Vol. 19(2014), p. 4510-4523.

[6] Paul P H But, Takeatsu Kimura, Ji-Xia Guo, et al. International Collation of Traditional and Folk Medicine: Northeast Asia Part II.World Scientific:Singapore,1997, p. 202-203.

[7] Jun-qing Zhang, Sheng Wang, Yong-hui Li, et al. Fitoterapia, Vol. 89(2013), p. 149-156.

[8] Feng Chen, Yong- hui Li, Yin-feng Tan, et al. Chemistry Central Journal, Vol. 7(2013), p. 131. 
[9] Zai-Jun Zhang, Lorita C.V.Cheang, Mei-wei Wang, , et al. Neurobiol. Vol. 32(2012), p. 27-40.

[10] Yong- hui Li, Feng Chen,Jun-fang Wang, et al. Chemistry Central Journal, Vol. 7(2013), p. 134.

[11]Wenjing Song, Yonghui Li, Jiangguo Wang, et al. Drug Test Anal, Vol. 6(2014), p. 239.

[12]Junqing Zhang, Yong Wang, Yonghui Li, et al. Arch Pharm Res, Vol. 35(2012) , p. 2143-2146.

[13] Weiyong Lai, Weili Yang, Mingsheng Liu, et al. China tropical medicine, Vol. 11(2011), p. 579-581. 